Dhaka Univ. J. Biol. Sci. 21(1): 67-77, 2012 (January)

\title{
HAEMATOLOGICAL PROFILE OF THAI AND INDIGENOUS MALE AND FEMALE AIR BREATHING CLIMBING PERCH
}

\author{
Mahmud Hasan*, Abdullah Al-Mamun and Md. Golam Rabbane \\ Department of Fisheries, University of Dhaka, Dhaka-1000, Bangladesh
}

Key words: Blood, Air breathing, Climbing Perch, Haematology

\begin{abstract}
This study evaluated the haematological profile of air breathing Thai and indigenous male and female climbing perch (in Bangla, koi) Anabus testudineus to improve understanding the differences between two strains at blood parameters level. Haemoglobin $(\mathrm{Hb})$, haematocrit (HCT), mean corpuscular volume (MCV), mean corpuscular haemoglobin $(\mathrm{MCH})$, mean corpuscular haemoglobin concentration (MCHC), erythrocyte red blood cells (RBC) or erythrocytes, lymphocytes, monocytes, neutrophils and eosinophils were identified by mythic 18 automated haematology analyzer. Most haematological parameters indicated significant $(\mathrm{p}<0.05)$ intra species sex variations. Higher $\mathrm{Hb}$ concentration, $\mathrm{RBC}$ counts and HCT percentages were found in Thai and indigenous males compared to their counterparts but higher $\mathrm{MCH}$ values, WBC counts and ESR levels were detected in both Thai and indigenous females than in the males. Similar concentration of $\mathrm{Hb}$ was detected in the same sex between fish. In contrast, higher level of ESR was observed in both female than did the males. Total counts of RBC observed in both Thai and indigenous male was significantly higher than in the females. MCV was found higher in indigenous male and female than in Thai one. However, no significant differences were observed in neutrophils, lymphocytes and eosinophils. Findings of this study showed sex variations in the haematological parameters between Thai and indigenous climbing perch.
\end{abstract}

\section{Introduction}

The blood volume of fishes varies between 2 and $8 \%$ of their body volume ${ }^{(1)}$. One third to one half of the total blood volume in fish consists of blood cells, the rest is fluid

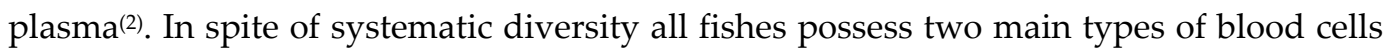
erythrocytes (red cells) and leucocytes (white cells), a property shared by the land living vertebrates, which are derived from early fishlike ancestors(3). A bibliography on fish hematology was assembled by Hawkins and Mawdesley-Thomas ${ }^{(4)}$. The major proteins of fish blood plasma are globulin to a large extent antibodies- immunoglobulin ${ }^{(1)}$. A peripheral blood serum from a healthy fish shows a preponderance of erythrocytes. Other cells are lymphocytes, neutrophils, monocytes, eosinophils, basophils and thrombocytes or platelets. Blood parameters of fishes may have species specific variations in cellular counts and biochemical values.

*Corresponding author. <mhasan@univdhaka.edu>. 
Air breathing climbing perch in Bangladesh is a commercially important high value fish. In Bangladesh two strains of climbing perch or koi (Thai and indigenous) are being farmed. However, although Thai and indigenous climbing perch both belong to the same genus and species (Anabas testudineus), due to geographical variation some differences at molecular level has been demonstrated by Tinni et al.(5). However, although a few literatures are available on the haematological parameters in various fishes of Bangladesh in which haematological parameters of climbing perch have never been reported. In India Banerjee( ${ }^{(6)}$ has reported on the haematological profiles of Anabas testudineus. He observed only some haematological parameters of koi. This study, therefore, was designed to see whether these two strains of koi vary between and among male and female in hematological parameters. This study will provide the basis for further studies on the taxonomy of this high value fish.

\section{Material and Methods}

Sexually matured air breathing climbing perch, Anabas testudineus of Thai (male: 11.2 $\pm 0.20 \mathrm{~cm}, 36.95 \pm 0.97 \mathrm{~g}$; female: $14.44 \pm 0.28 \mathrm{~cm}, 52.16 \pm 1.17 \mathrm{~g}$ ) and indigenous (male: $8.31 \pm 0.11 \mathrm{~cm}, 23.68 \pm 0.63 \mathrm{~g}$; female: $10.79 \pm 0.10 \mathrm{~cm}, 42.72 \pm 0.52 \mathrm{~g}$ ) were used as experimental animals obtained from Mymenshingh and Natore districts, Bangladesh. This was a $2^{2}$ factorial study in triplicates. The study was conducted between May and August, 2008.

The experimental variables were the levels of various blood parameters such as haemoglobin $(\mathrm{Hb})$, erythrocyte sedimentation rate (ESR), red blood cells (RBC), haematocrit $(\mathrm{HCT})$, mean corpuscular volume (MCV), mean corpuscular haemoglobin $(\mathrm{MCH})$, mean corpuscular haemoglobin concentration (MCHC), white blood cells (WBC), differential neutrophils, lymphocytes, monocytes, eosinophils and basophils counts.

Thai climbing perch was identified using their blotches unlike indigenous ones following Tinni et al.(5) Matured male and female fish were identified based on the external characteristics. Females were selected based on the body color and deep brown pelvic fin. Males on the other hand, were identified depending upon the glazy black coloration in the body and reddish hue on the pectoral and ventral fins.

Samples of blood were drawn by severing the caudal peduncle which is suitable for smaller fish and in many cases may be the only option because the blood vessels are small and blood volumes are very low. A sample of $2 \mathrm{ml}$ blood was collected by using 3 $\mathrm{ml}$ plastic syringes treated with an anticoagulant: EDTA from $(\mathrm{n}=5)$ and held in sample test tube containing K3 EDTA solution. Blood parameters were assayed by using Mythic 18 Automated Haematology Analyzer (China). This instrument analyzes the blood parameters using three detector blocks and two types of reagents. To analyze haemoglobin by automated methods, the cyanmethemoglobin method or oxyhaemoglobin method was applied. 
Data were expressed as mean \pm standard error of the means. Neutrophils, lymphocytes, monocytes, eosinophils and basophils data were transformed into square root before statistical analysis. Differences between and within both male and female Thai and indigenous koi were compared by using t-test. Statistical software SPSS version 11.5 was used to analyze data with the levels of significance at $p<0.05$.

\section{Results and Discussion}

Significantly higher $\mathrm{Hb}$ concentrations were found in both Thai and indigenous male (Thai: $11.63 \pm 0.22 \mathrm{~g} \mathrm{~d} / \mathrm{l}$; indigenous: $13.27 \pm 0.69 \mathrm{~g} \mathrm{~d} / \mathrm{l}$ ) than their female counterparts (Thai: $10.07 \pm 0.20 \mathrm{~g} \mathrm{~d} / \mathrm{l}$; indigenous: $9.8 \pm 0.12 \mathrm{~g} \mathrm{~d} / \mathrm{l}$ ) while compared (Fig. 1). However, there was no significant difference within groups.

The observed higher $\mathrm{Hb}$ concentration found in males compared to females indicates sex differences. Males are more active and aggressive than the female, which, is in agreement with Smith et al.(7). Hb concentration in different fishes living in similar water bodies may vary with each other considerably, but the variation in the same species is very little. The observed similar $\mathrm{Hb}$ concentration in the same sex between two fish is expected ${ }^{(8)}$. Levels of $\mathrm{Hb}$ found in both sexes of Thai and indigenous koi was above $9 \mathrm{~g}$ $\mathrm{d} / \mathrm{l}$, which denotes the occurrence of no anaemic condition ${ }^{(9)}$. The concentration of $\mathrm{Hb}$ found in C. batrachus ranged $8.0-19.2 \mathrm{~g} \mathrm{~d} / 1$ with an average of $14.24 \pm 0.66 \mathrm{~g} \mathrm{~d} / \mathbf{l}^{(10)}$.

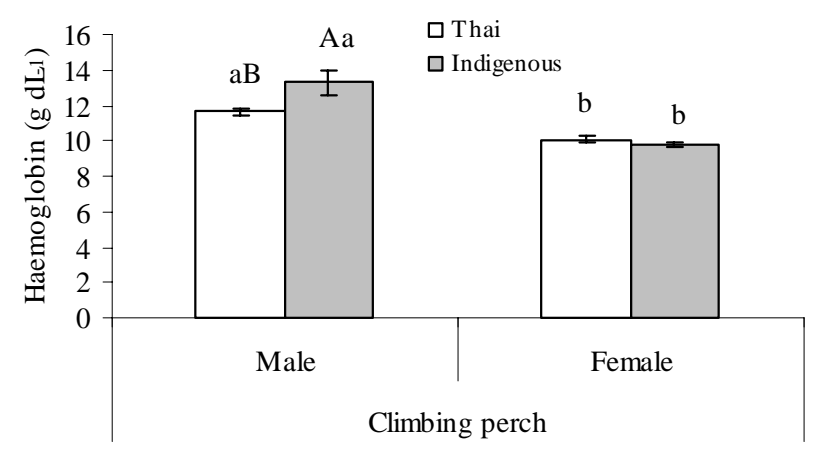

Fig. 1. Levels of hemoglobin $(\mathrm{Hb})$ in sexually matured Thai and indigenous climbing perch, $A$. testudineus sampled in male and female fish. Bars (mean \pm SEM) with same color different letters are significantly different $(\mathrm{p}<0.05)$.

Both Thai and indigenous female (Thai: $36.00 \pm 2.52 \mathrm{~mm}$, 1st h; indigenous: $42.67 \pm$ $1.76 \mathrm{~mm}, 1 \mathrm{st}$.) had significantly higher ESR levels than in the males (Thai: $1.33 \pm 0.33$ $\mathrm{mm}, 1 \mathrm{st}$ h; indigenous: $1.67 \pm 0.33 \mathrm{~mm}, 1 \mathrm{st} \mathrm{h}$.) while compared (Fig. 2). However, no significant differences were found within groups.

The observed level of ESR in both male was fewer than $10 \mathrm{~mm}$, 1st h which indicates the normal physiological condition. Higher levels of ESR detected in both female than males could be because of the production of large number of eggs compared to the 
sperms in male. Similar observation was found by Mishra et al.(11) in Amphipnous cuchia. The observed higher ESR in females indicates the chances of occurrence of infections because at high ESR chronic inflammatory conditions, connective tissue diseases, anaemia etc. may attack fishes. ESR is used as the indicator of the general health of the fish $^{(12)}$. It has also been used for the early detection of infections in Salvelinus fontinalis(13).

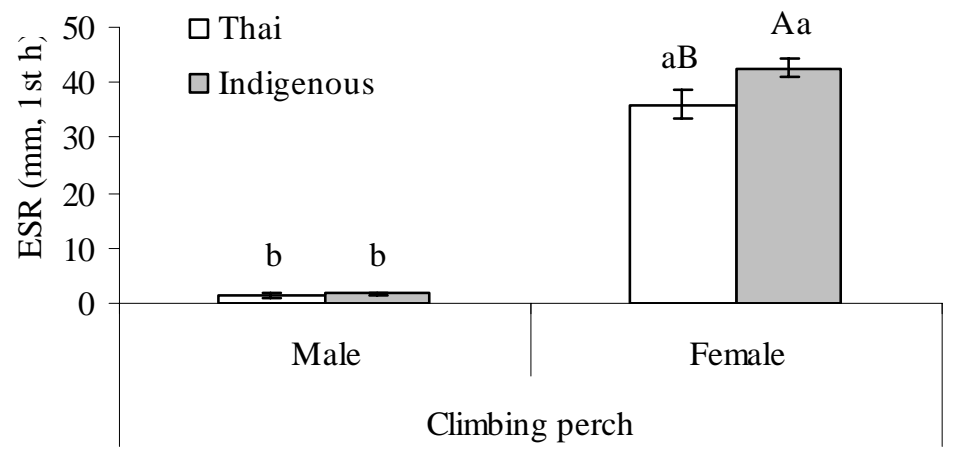

Fig. 2. Erythrocyte sedimentation rate (ESR) of sexually matured Thai and indigenous climbing perch, A. testudineus sampled in male and female fish. Bars (mean \pm SEM) with same color different letters are significantly different $(\mathrm{p}<0.05)$.

While comparing, total counts of RBC observed in both Thai and indigenous male (Thai: $2.92 \pm 0.08 \mathrm{~m} / \mathrm{ml}$; indigenous: $3.03 \pm 0.23 \mathrm{~m} / \mathrm{ml}$ ) were significantly higher than in the females (Thai: $2.14 \pm 0.11 \mathrm{~m} / \mathrm{ml}$; indigenous: $1.9 \pm 0.10 \mathrm{~m} / \mathrm{ml}$ ) (Fig. 3). However, RBC counts within male and female groups were similar.

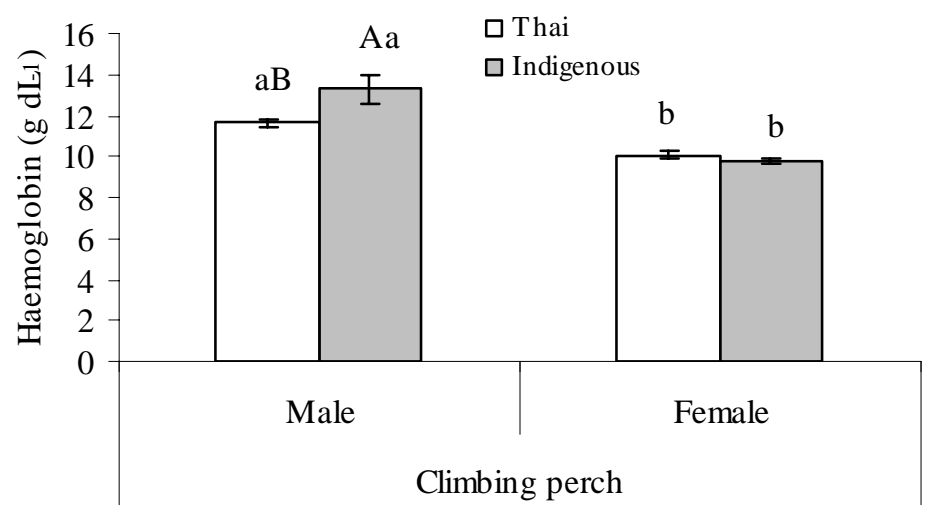

Fig. 3. Levels of Red Blood cells (RBC) in sexually matured Thai and indigenous climbing perch, $A$. testudineus sampled in male and female fish. Bars (mean \pm SEM) with same color different letters are significantly different $(\mathrm{p}<0.05)$. 
RBC containing hemoglobin plays a vital role in respiration described by Wells et al.(8). The present data of RBC count was similar to the range found by Banerjee( ${ }^{(6)}$ in the same fish. Present study showed higher RBC counts in males than the females which denote sex variations. The observed higher RBC counts in males perhaps because of their hyperactiveness compared to the females. RBC counts have proven to be a highly variable blood parameter among fishes and showed a remarkable difference in their sex. Svobodova et al.(14) also found higher RBC in males of seven fish species.

HCT (\%) observed in both Thai and indigenous male (Thai: $33.33 \pm 1.67 \%$; indigenous: $50.67 \pm 3.76 \%$ ) were significantly higher than in the females (Thai: $26.33 \pm$ $1.20 \%$; indigenous: $30.33 \pm 0.88 \%$ ) while compared (Fig. 4). However, indigenous male had higher level of HCT value (50.67 $\pm 3.76 \%)$ than that of Thai ones $(33.33 \pm 1.67 \%)$.

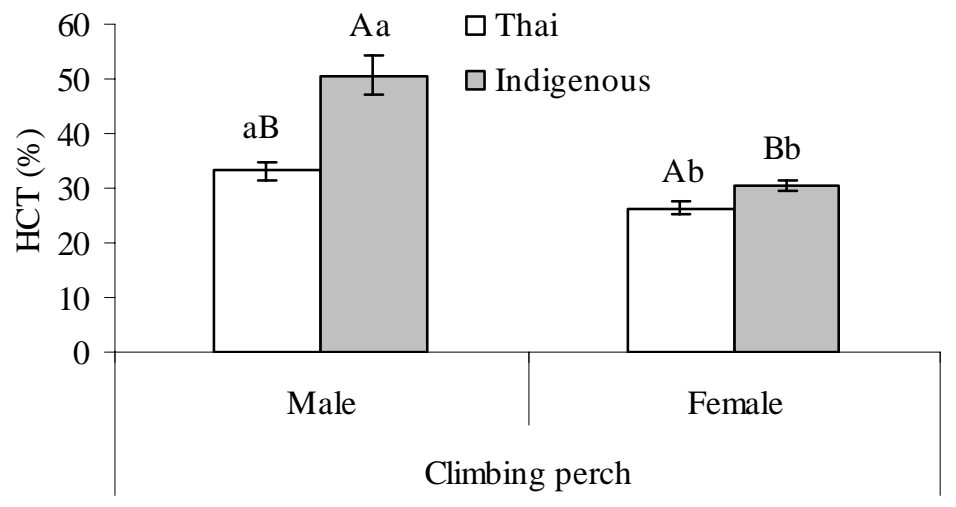

Fig. 4. Haematocrit (HCT) levels in sexually matured Thai and indigenous climbing perch, A. testudineus sampled in male and female fish. Bars (mean \pm SEM) with same color different letters are significantly different. Capital letters denote significant differences within group $(\mathrm{p}<0.05)$.

Both Thai and indigenous males had significantly higher value of HCT than in the females that perhaps because of relatively higher RBC counts in males. The likely another reason could be of sex difference where males may remain stressed from hyperactivity in nature( ${ }^{(9)}$. A lower haematocrit value in females indicates iron deficiency anaemia and relatively low RBC count etc.

Indigenous male $(167.33 \pm 1.20 \mathrm{fL})$ and female $(160.00 \pm 4.16 \mathrm{fl})$ had significantly higher levels of MCV than the levels measured in Thai koi (male: $114.00 \pm 2.52 \mathrm{fl}$; female: $124.33 \pm 11.26 \mathrm{fl}$ ) while compared (Fig. 5).

MCV value reflects the size of red blood cells by expressing the volume occupied by a single red blood cell. Normal value varies according to the species, sex, age etc. Increased value of $\mathrm{MCV}$ in indigenous fish compared to the Thai ones indicates macrocytic anaemia or folic acid deficiency as expected ${ }^{(15)}$. The higher MCV value observed in indigenous male than that of Thai ones could be because of lower HCT 
value. Indigenous female had higher value of MCV compared to Thai female which could be due to higher RBC.

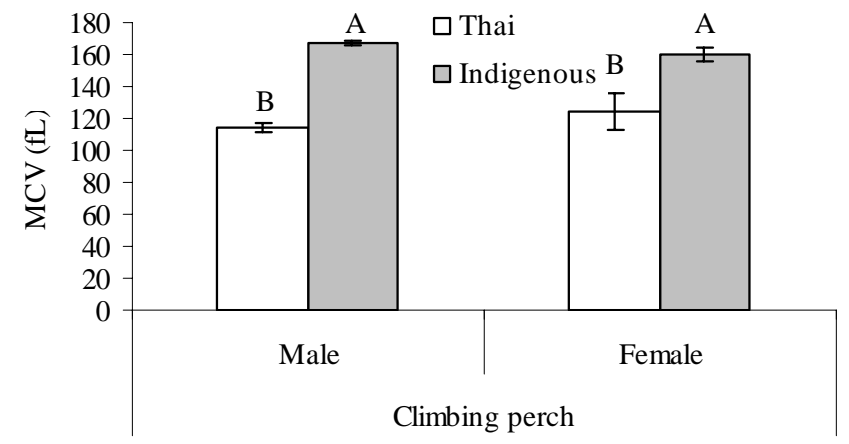

Fig. 5. Levels of mean corpuscular volume (MCV) in sexually matured Thai and indigenous climbing perch, Anabas testudineus sampled in male and female fish. Bars (mean \pm SEM) with same color are not significantly different. Capital letters denote significant difference within group $(\mathrm{p}<0.05)$.

$\mathrm{MCH}$ levels observed in both Thai and indigenous female (Thai: $47.33 \pm 2.40 \mathrm{pg}$; indigenous: $52.00 \pm 2.08 \mathrm{pg}$ ) were significantly higher than the levels measured in the male (Thai: $39.67 \pm 0.67 \mathrm{pg}$; indigenous: $44.00 \pm 2.65 \mathrm{pg}$ ) while compared (Fig. 6). But no significant differences were detected within group of male and female.

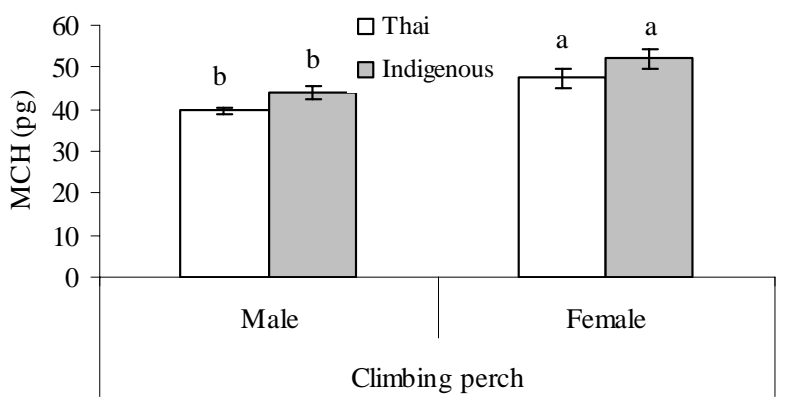

Fig. 6. Levels of mean corpuscular hemoglobin $(\mathrm{MCH})$ in sexually matured Thai and indigenous climbing perch, $A$. testudineus sampled in male and female fish. Bars (mean \pm SEM) with same color different letters denote significant differences $(p<0.05)$.

Observed higher $\mathrm{MCH}$ value in both Thai and indigenous females than in the males indicates higher likelihood of occurrence of macrocytic anaemia in females than in males $^{(15)}$.

In comparing, MCHC found in indigenous female $(32.33 \pm 0.67 \mathrm{~g} / \mathrm{dl})$ was significantly higher than in the indigenous male $(26.33 \pm 0.67 \mathrm{~g} / \mathrm{dl}$; Fig. 7$)$. However, Thai male had higher level of MCHC $(35.00 \pm 1.00 \mathrm{~g} / \mathrm{dl})$ than that of indigenous $(26.33 \pm 0.67$ $\mathrm{g} / \mathrm{d})$ ones. 


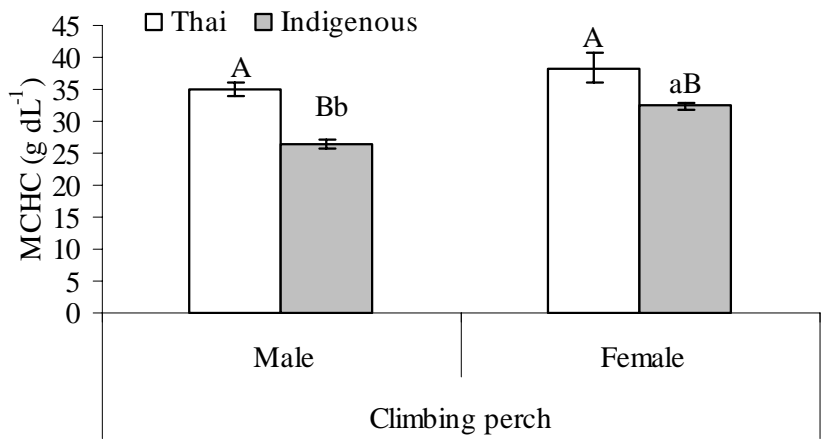

Fig. 7. Mean corpuscular hemoglobin concentration (MCHC) in sexually matured Thai and indigenous climbing perch, $A$. testudineus sampled in male and female fish. Bars (mean \pm SEM) with same color different letters are significantly different. Capital letters denote significant differences within group $(\mathrm{p}<0.05)$.

Occurrence of higher levels of $\mathrm{MCHC}$ in Thai male compared to the indigenous ones could have resulted perhaps because of lower levels of haematocrit found in Thai male than in indigenous ones. The observed higher level of MCHC in indigenous female than their male counterparts could be explained by sex differences. High levels of MCHC indicate more $\mathrm{Hb}$ in a unit of $\mathrm{RBCs}^{(15)}$. In case of fish $\mathrm{MCHC}$ there is no prescribed normal range. In teleosts this has been found species specific. The levels of $\mathrm{MCHC}$ have been detected 38.57, 29.93 and $27.16 \mathrm{~g} / \mathrm{dl}$ in Labeo rohita, Clarias batrachus and Channa punctatus, respectively ${ }^{(16)}$.

Total WBC counts detected in both Thai and indigenous female (Thai: $8.6 \pm 0.27 \times 10^{4}$ $\mathrm{cu} / \mathrm{mm}$; indigenous: $9.05 \pm 0.36 \times 10^{4} \mathrm{cu} / \mathrm{mm}$ ) were significantly higher than the levels measured in the males (Thai: $6.82 \pm 0.36 \times 10^{4} / \mathrm{cu} \mathrm{mm}$; indigenous: $5.04 \pm 0.32 \times 10^{4}$ $\mathrm{cu} / \mathrm{mm}$ ) while compared (Fig. 8). However, WBC count was higher in Thai male (6.82 \pm $\left.0.36 \times 10^{4} \mathrm{cu} / \mathrm{mm}\right)$ than that of indigenous $\left(5.04 \pm 0.32 \times 10^{4} \mathrm{cu} / \mathrm{mm}\right)$ ones.

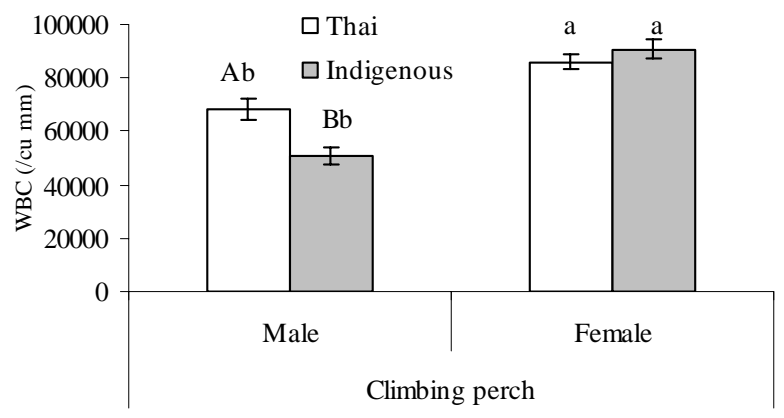

Fig. 8. White blood cells (WBC) levels in sexually matured Thai and indigenous climbing perch, Anabas testudineus sampled in male and female fish. Bars (mean \pm SEM) with same color different letters are significantly different. Capital letters denote significant differences within group $(\mathrm{p}<0.05)$. 
Observed WBC in both Thai and indigenous female were significantly higher than the levels measured in the males, which indicate egg carriage, infection, adverse condition $^{(17)}$. Detected higher WBC value in Thai male compared to indigenous ones indicates the possibility of occurrence of infections, iron deficiency and anaemia etc. Levels of WBC in climbing perch are considerably higher than the level of man (Normal range: $4000-11000 \mathrm{cu} / \mathrm{mm}$ ) as expected ${ }^{(18)}$. In fishes the significance of $\mathrm{WBC}$ and their biological function are not clearly understood. The number in some species of fish varies greatly with age, season and maturation ${ }^{(19)}$.

Percentage composition (\%) of neutrophils found in both male and female Thai and indigenous male (Thai: $18.67 \pm 2.03 \%$; indigenous: $21.67 \pm 1.33 \%$ ) were similar (Thai: 22.67 $\pm 1.45 \%$; indigenous: $18.33 \pm 2.03 \%$; Fig. 9).

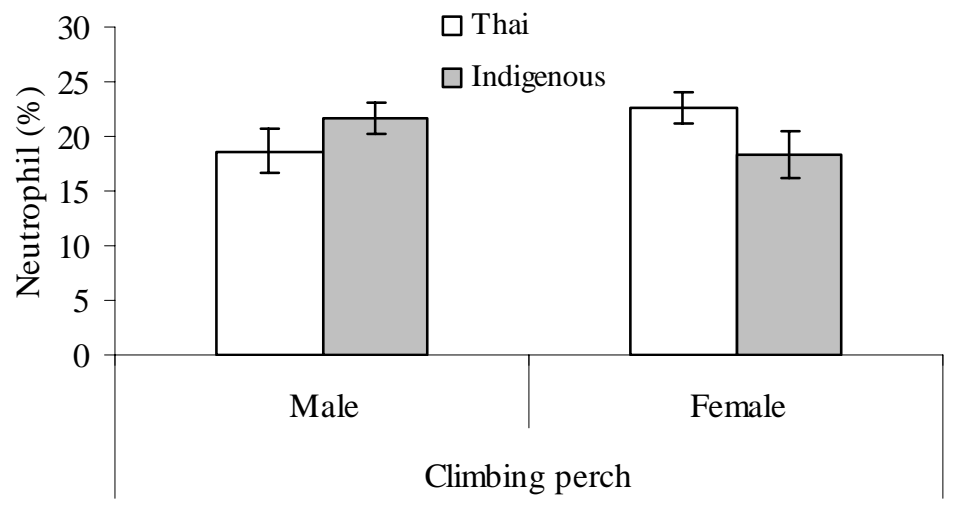

Fig. 9. Percentage composition of neutrophil in sexually matured male and female Thai and indigenous climbing perch, A. testudineus. Bars (mean \pm SEM) with same color no letters denote no significant difference $(\mathrm{p}>0.05)$.

Neutrophils are the most important of the leucocytes as they show the greatest sensitivity to change in the environment. Their characterization and identification is, therefore, of significance for assessing the changes in the physiological state of fishes.

Sexually matured Thai and indigenous male and female (Thai: $75.00 \pm 2.89 \%$; indigenous: $71.33 \pm 1.86 \%$ ) had similar levels of lymphocytes count (Thai: $72.33 \pm 1.86 \%$; indigenous: $75.33 \pm 2.60 \%$; Fig. 10). Similarly, no difference was detected in the lymphocyte (\%) composition within male and female groups.

Lymphocytes were regarded as multi potential haemopoietic stem cells ${ }^{(20)}$ but now they are regarded as highly differentiated cells with immunological stimuli in various ways and known as immune-competent cells. Similar lymphocytes in both sexes of Thai and indigenous koi denote similar immune levels. This similar immune level could be because of healthy fish farmed in farms and natural environment. 
Similar level monocyte (\%) was measured both in Thai male $(2.33 \pm 0.33 \%)$ and in the female $(1.33 \pm 0.33 \%)$ and within groups (Fig. 11).

Differential leucocyte counts in Thai and indigenous koi confirmed the presence of monocytes in teleost blood which is in agreement with Ellis(21). Similar leucocytes count in both sexes of Thai and indigenous koi indicates that leucocytes count do not vary between sexes. The percentage of monocyte found in some fishes were $37 \%$ with an average of $4.89 \pm 1.94 \%$ ) in Clarias batrachus ${ }^{(10)}$.

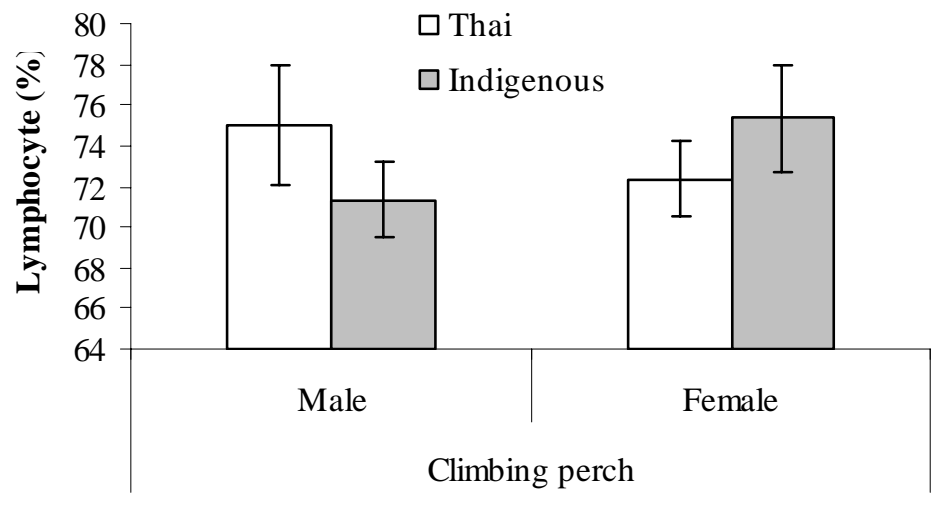

Fig. 10. Lymphocytes (\%) in sexually matured male and female Thai and indigenous climbing perch, A. testudineus, respectively. Bars (mean \pm SEM) with same color denotes no significant difference $(\mathrm{p}>0.05)$.

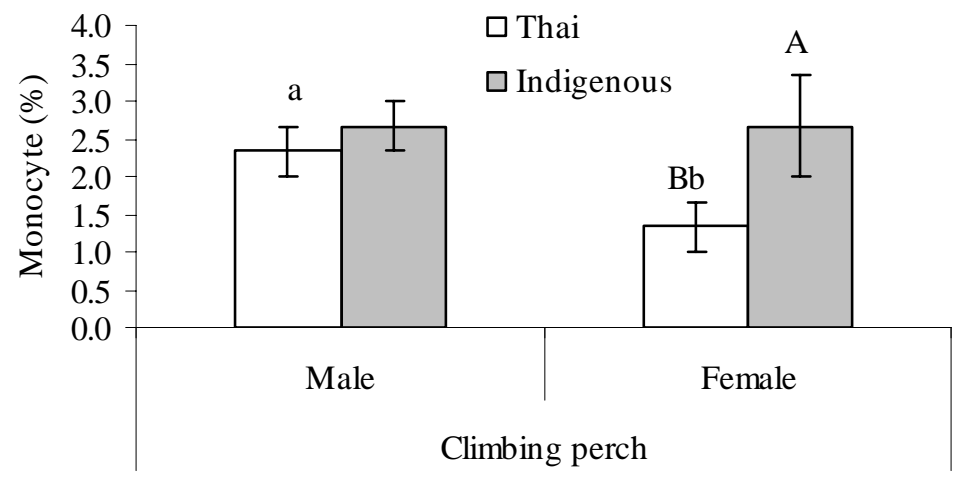

Fig. 11. Levels of monocytes in sexually matured Thai and indigenous climbing perch, Anabas testudineus sampled in male and female fish. Bars (mean \pm SEM) with same color are not significantly different $(p>0.05)$.

Both Thai and indigenous (Thai: $4.00 \pm 0.58 \%$; indigenous: $4.33 \pm 0.67 \%$ ) male and female (Thai: $3.67 \pm 0.88 \%$; indigenous: $3.67 \pm 0.67 \%$ ) had similar composition of eosinophils (\%, Fig. 12). 


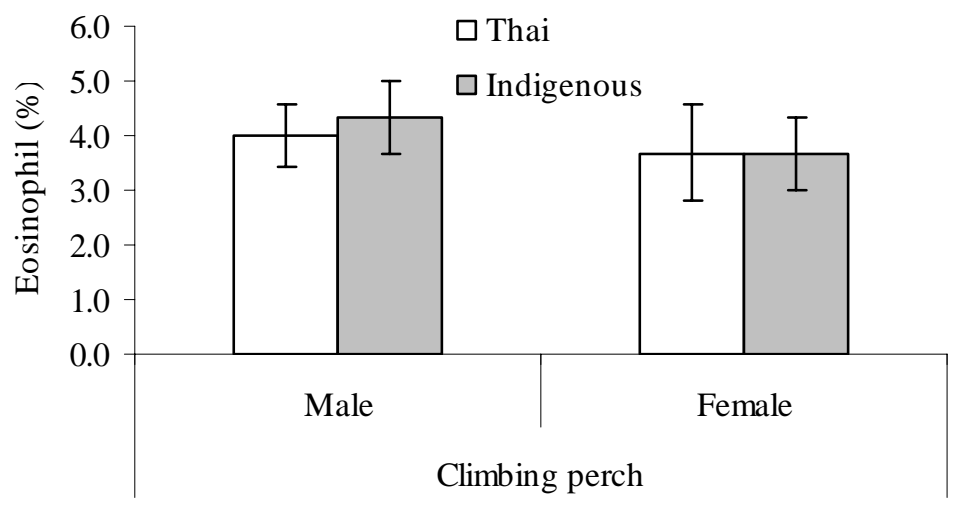

Fig. 12. Percentage of eosinophils in sexually matured Thai and indigenous climbing perch, $A$. testudineus sampled in male and female fish. Bars (mean \pm SEM) with same color denotes no significant difference $(\mathrm{p}>0.05)$.

According to Ellis ${ }^{(21)}$ presence and absence of fish eosinophil are contradictory. While the previous workers opted for their absence, recent workers opted for their presence. During present investigation eosinophil was detected which deny the absence of eosinophil opted by earlier workers. The observed no difference in eosinophil counts between sexes of indigenous and Thai koi shows similar physiological condition in terms of WBC differential counts. Eosinophil percentages detected in C. batrachus is $0-3 \%$ with an average of $0.72 \pm 0.18 \%{ }^{(10)}$.

\section{References}

1. Fange R 1994. Blood cells, haemopoisis and lymphomyeloid tissues in fish. Fish and Shellfish Immunology 4: 405-411.

2. Wedemeyer RW and MC Warner 1976. Some observations on the stained blood cellular elements of channel catfish, Ictalurus punctatus. J. Fish Biol. 9: 491-497.

3. Nelson JS 1984. Fishes of the world, $2^{\text {nd }}$ ed., John Wiley and Sons, New York.

4. Hawkins and Mawdesley-Thomas 1972. Fish hematology-bibliography. J. Fish Biol. 4: 193-232.

5. Tinni SR Jessy NS Hasan MM Mustafa MG and SkS Alam 2007. Compararative karyotype analysis with differential spaining in two forms of Anabas testudineus (Bloch), Cytologia 72(1): 1-5.

6. Banerjee V 1966. A note on the haematological studies of Anabas testudineus (Bloch) Sci. \& Cult. 32: 326-327.

7. Smith CG, Lewis WM and HM Kaplan 1952. A comparative morphology and physiologic study of fish blood. The Prog. Fish-Cult. 14: 169-197.

8. Wells RM, Ashby MD, Duncan SJ and JA McDonald 1980. Comparative study of the erythrocytes and hemoglobin in nototheniid fishes from Antarctica. J. Fish-Biol. 17: 5175279 . 
9. Naser MN 2000. Role of Iron in Atlantic Salmon (Salmo salar) Nutrition: Requirements, Bioavailability, Disease Resistance and Immune response. Ph.D. Thesis. Dalhousie University. pp. 282.

10. Naser MN and MA Liza 2007. Some haematological parameters of adult magur, Clarias batrachus (Linnaeus 1758) from a culture pond of Dhaka, Bangladesh. Bangladesh J. Zool. 35: 71-80.

11. Mishra N, Pandey JS, Datta Munshi, JK.and BR Singh 1977. Haematological parameters of an air breathing mid eel, Amphipnous cuchia (Ham.) (Amphipnoidae: Pisces). J. Fish Biol. 10: 567-573.

12. Khaleque KA 1987. Practical Pathology. $7^{\text {th }}$ ed. Polwel Printing Press, Dhaka, Bangladesh. $623 \mathrm{p}$.

13. Schumacher RE, Hamilton CH and EJ Longtin 1956. The Prog. Fish. Cult. 18: 147-148.

14. Svobodova H, Kroupova H, Modra H, Flajshans M, Randak T, Savina LV and D Gela 2008. Haematological profile of common carp spawners of various breeds. J. Appl. Ichthyol. 24: 55-59.

15. Robbins SL, Cotran RS and V Kumar 1974. Pathologic basis of disease. 5th ed. W.B. Saunders Company. pp. 583-615.

16. Sharma RK and S Shandilya 1982. Observations on haematological values of some freshwater teleosts. Comp Physiol Ecol. 7(2): 124-126.

17. Smith LS 1986. Introduction of fish physiology. Indian Edition by Narendra Publishing House, Delhi, India. pp. 322-333.

18. Andrews W 1965. Comparative haematology, Grune and Starttin, Inc. New York, pp.188.

19. Puchkov NV 1964. The white blood cells. Techniques for the investigations of fish physiology. Isrial. Prog. Sci. Trans. pp. 11-15.

20. Yoffe JM and FC Courtice 1970. "Lymphatics, Lymph and the Lympfomyeloid complex" Academic Press, New York.

21. Ellis AE 1977. The leucocytes of fishes: a review. J. Fish Biol. 11: 453-490.

(Manuscript received on 9 April, 2011; revised on 16 November, 2011) 